\section{Aboriginal populations and youth suicide}

Swanson and Colman provide a muchneeded analysis of associations between exposure to suicide and suicidality outcomes among Canadian youth.

Youth suicide in Canada cannot be fully understood without consideration of First Nations, Inuit or Métis populations. Some researchers conclude that suicide among Aboriginal people must be considered a different disease from suicide among non-Aboriginal people, with its own antecedent causes. ${ }^{2,3}$ Suicide rates are 5 to 7 times higher for First Nations youth than for non-Aboriginal youth, and rates among Inuit youth are about 11 times the national average. ${ }^{4,5}$ Suicide clusters among First Nations youth have been widely reported. ${ }^{4,6}$

Swanson and Colman are mistaken in their description of their data source as a "population-based nationally representative cohort." The Canadian National Longitudinal Survey of Children and Youth "excludes children living on Indian reserves or Crown lands ... and residents of some remote regions." Such an exclusion should have been identified and addressed among the study's limitations.

Researchers and editors must attend to health equity dimensions of their work, especially when allegedly representative data prevents us from attending to underserviced groups. Not only are there disparities between the health of Aboriginal and non-Aboriginal Canadians, but an epidemiological gap prevents researchers from understanding and addressing such problems. Some scholars have expressed concern that a lack of data sources including Aboriginal populations may represent a "concerted effort by the government to diminish the collection of data about Aboriginal health conditions."

Aboriginal leadership and national agencies have called for research to take place through reciprocal trusting relationships between researchers and
Aboriginal people. ${ }^{9}$ This should never offer a convenient excuse to exclude Aboriginal peoples from national studies when such a relationship has not been established. Scholars exploring subjects with important Aboriginal dimensions should have to defend choices to overlook these populations in purportedly national or representative studies.

\section{Aaron M. Orkin MD MSc, Nikhil Rajaram MD MPH, Michael Schwandt MD MPH}

Dalla Lana School of Public Health, University of Toronto, Toronto, Ont.

\section{References}

1. Swanson SA, Colman I. Association between exposure to suicide and suicidality outcomes in youth CMAJ 2013:185:870-7.

2. Cutcliffe JR. Toward an understanding of suicide in First-Nation Canadians. Crisis 2005;26:141-5.

3. MacNeil MS. An epidemiologic study of Aboriginal adolescent risk in Canada: the meaning of suicide. J Child Adolesc Psychiatr Nurs 2008;21:3-12.

4. First Nations and Inuit Health: suicide prevention. Ottawa (ON): Health Canada; 2006. Available: www.hc-sc.gc.ca/fniah-spnia/promotion/suicide /index-eng.php (accessed 2013 May 28).

5. Whitehead S, Henning B, Johnston J, et al. Developing an injury morbidity and mortality profile in the Sioux Lookout zone: 1992-1995. Project supported by the Canadian Hospitals Injury Reporting and Prevention Program; 1996.

6. First Nation hit hard by "suicide contagion." CBC.ca 2013 May 24. Available: www.cbc.ca/news /canada/thunder-bay/story/2013/05/24/sby-sudburythunder-bay-suicide-contagion-psychologist-firstnation.html (accessed 2013 May 28).

7. Human Resources and Skills Development Canada and Statistics Canada. Growing up in Canada: National Longitudinal Survey of Children and Youth. Ottawa (ON): Statistics Canada; 1996. Available: www23.statcan.gc.ca/imdb/p2SV.pl? Function=getSurvey $\&$ SDDS $=4450 \& I t e m \_I d=256$ 09\&lang=en (accessed 2013 May 28).

8. Webster PC. Aboriginal health programming under siege, critics charge. CMAJ 2012;184:E739-40.

9. Research Involving the First Nations, Inuit, and Métis Peoples of Canada. Ottawa (ON): Panel on Research Ethics; 2012. In: Tri-Council policy statement: ethical conduct for research involving humans. Available: www.pre.ethics.gc.ca/eng/policy-politique/initiatives /tcps2-eptc2/chapter9-chapitre9/\#toc09-intro (accessed 2013 May 28).

CMAJ 2013. DOI:10.1503/cmaj.113-2139

\section{The authors respond}

We agree with Orkin and colleagues ${ }^{1}$ that addressing suicidal behaviour within Aboriginal communities in Canada should be an urgent priority for research and public health action. We support all actions to work with these communities to better understand this complex phenomenon, and to intervene through evidence-based prevention and postvention approaches.

Sonja A. Swanson ScM, Ian Colman PhD Department of Epidemiology (Swanson), Harvard School of Public Health, Boston, Mass.; Department of Epidemiology and Community Medicine (Colman),

University of Ottawa, Ottawa, Ont.; School of Public Health (Colman), University of Alberta, Edmonton, Alta.

\section{Reference}

1. Orkin AM, Rajaram N, Schwandt M. Aboriginal populations and youth suicide [letter]. CMAJ 2013; 185:1347.

CMAJ 2013. DOI:10.1503/cmaj.113-2140

\section{Deathless models of aging: time to reform CanMEDS}

Cosco and colleagues deserve accolades for their article in $C M A J{ }^{1}$

Although there may be many factors that have led to the development of a death-denying culture, we believe that the main driver relates to deficiencies within medical education. Medical curricula are driven by competency frameworks. During the early 1990s, the Royal College of Physicians and Surgeons of Canada created the Canadian Medical Education Directives for Specialists (CanMEDS). ${ }^{2}$ With an aim to improve patient care and outcomes in a continuously evolving health care environment, this globally recognized framework encompasses 7 essential roles (competencies) all physicians must fulfill to be effective health care providers: medical expert, communicator, collaborator, manager, health advocate, scholar and professional. The CanMEDS framework serves as an integral part of Canadian medical education and practice, as it forms the basis for the training objectives of all medical specialties and subspecialties recognized by the Royal College. ${ }^{2}$ Currently, the framework is undergoing a 3 -year reform with the goal of aligning with a competency-based approach to medical education by 2015 .

We conducted a content analysis of 

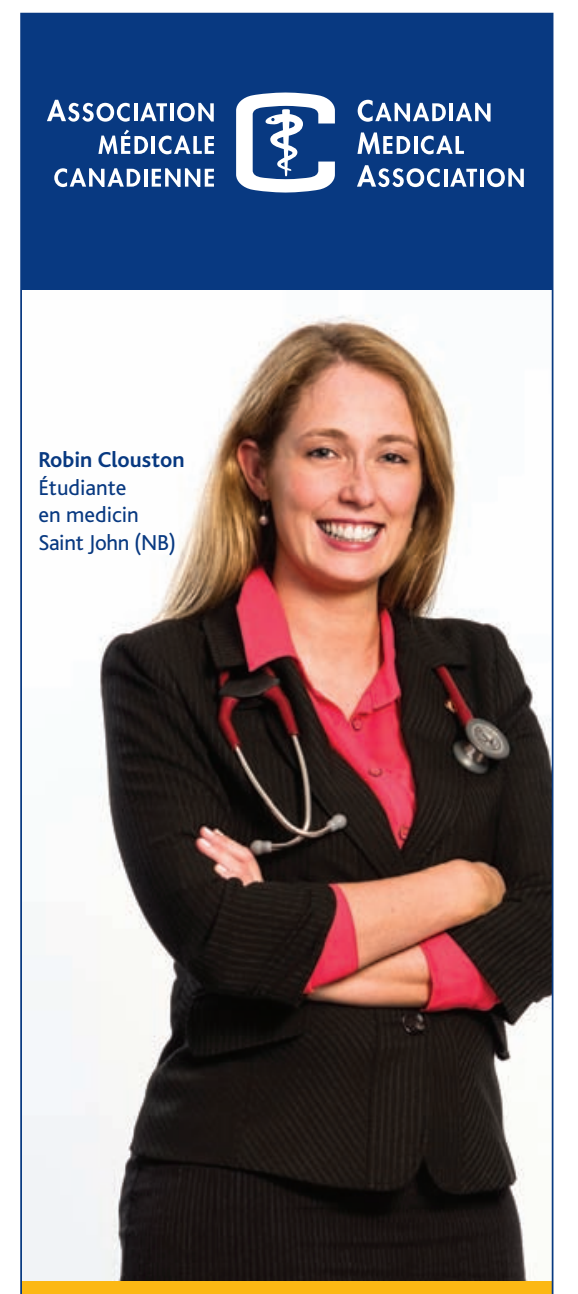

\section{LA VALEUR DE L'ADHÉSION}

Solutions de gestion globale du patrimoine

- Ressources et outils cliniques en ligne

- JAMC

- Représentation et promotion

$\longrightarrow$

Pour connaître tous les avantages de l'adhésion, composer le 888-855-2555 ou consulter amc.ca/membres

\section{LETTERS}

the CanMEDS Objectives of Training in the Subspecialty of Geriatric Medicine (2012, Version 1.0) using Foxit Reader 5.1 software. We scanned the document for keywords that are pertinent to the delivery of timely palliative care services to geriatric patients. Only brief mention of "end of life care," "end-of-life care," and "prognostic factors" are found in the "Medical Expert" section. Completely absent are the following keywords: prognosis, prognosticate, prognostication, life expectancy, survival estimate, natural history of disease, palliative, palliation and palliative care. None of the aforementioned keywords were found within the sections that outline the other 6 roles.

For palliative care to be delivered in a timely fashion, physicians must skillfully discuss the diagnosis and natural history of the disease, together with the formulation of a prognosis and the communication of that prognosis to the patient and/or substitute decisionmaker. In a truly patient-centred manner, the patient and/or substitute decision maker may then choose either to proceed with an active, aggressive medical micromanagement mode or a conservative palliative mode (i.e., pain and symptom management). ${ }^{3}$

The deathless models of aging described by Cosco and colleagues ${ }^{1}$ represents an epiphenomenon that we believe is the result of deficiencies within medical education. It behooves competency frameworks such as Can-
MEDS to incorporate competencies that will enable the timely transitioning of patients toward conservative palliative philosophies of care that promote comfort, dignity, quality of life and quality of death. At the root of this process is the restoration of prognosis as a core competency in medical practice.

Vincent Maida MD MSc, Paul M. Cheon HBHSc MD (cand)

Associate Professor (Maida), Division of Palliative Care, University of Toronto; Faculty of Medicine (Cheon), University of Toronto, Toronto, Ont.

\section{References}

1. Cosco TD, Stephan BCM, Brayne C. Deathless models of aging and the importance of acknowledging the dying process. CMAJ 2013;185:751-2.

2. CanMEDS. Ottawa (ON): Royal College of Physicians and Surgeons of Canada. Available: www .royalcollege.ca/portal/page/portal/rc/canmeds (accessed 2013 July 27).

3. Maida V, Peck J, Brar N, et al. Preferences for active and aggressive interventions among patients with advanced cancer. BMC Cancer 2010;10:592.

CMAJ 2013. DOI:10.1503/cmaj.113-2138

\section{Letters to the editor}

In submitting a letter, you automatically consent to have it appear online and/or in print. All letters accepted for print will be edited by $C M A J$ for space and style. The full version of any letter that appears in print is available at cmaj.ca. Competing interests will appear online only. 